\title{
CAPÍTULO 17: CARACTERIZACAO FÍSICO-QUÍMICA DO LEITE, QUEIJO E QUEIJO MISTO MATURADO DE OVELHA CRIOULA
}

\section{CHAPTER 17: PHYSICOCHEMICAL CHARACTERIZATION OF MILK AND MATURE CHEESE FROM CRIOULA SHEEP}

\author{
Shara Vargas Roque ${ }^{1}$; Diogo Maus ${ }^{2}$
}

\begin{abstract}
Resumo
A produção do leite ovino tem aumentado, sendo a região sul responsável por $20,3 \%$ do total produzido no Brasil. No Rio Grande do Sul, a fronteira oeste tem destaque na criação de ovelhas Crioulas, que associada a produção de leite, se apresenta como uma alternativa sustentável de baixo investimento e de fácil implementação pela agricultura familiar, trazendo alternativas de renda para as pequenas e médias propriedades rurais. Dessa forma, o objetivo do trabalho foi a produção de queijo maturado a partir do leite de ovelhas Crioulas e de leite misto (mistura de leite de ovelha Crioula com leite bovino). Foram realizadas 2 formulações de queijos, sendo a primeira somente com leite de ovelhas Crioulas e outro com leite misto (50\% leite de ovelha: $50 \%$ leite bovino). Os queijos foram submetidos a caracterização físico-química e de textura. O queijo produzido com leite de ovelha Crioula apresentou maior teor de proteína e menor teor de gordura em relação ao queijo produzido a partir do leite misto. A textura dos queijos produzidos com leite de ovelha Crioula apresentou maiores valores de dureza, mastigabilidade e coesividade.
\end{abstract}

Palavras-Chaves: Ovelha Crioula, Leite, Queijo, Textura.

\begin{abstract}
Sheep milk production has increased, with the southern region accounting for $20.3 \%$ of the total produced in Brazil. Rio Grande do Sul, the western border is highlighted in the creation of Creole sheep, which associated with milk production, presents itself is a sustainable alternative, with low investment and easy implementation by family farming, bringing income alternatives to small and medium-sized rural properties. Thus, the aim of the work was the production of matured cheese from the milk of Crioula sheep and mixed milk (mixture of Crioula sheep milk and bovine milk). Two cheese formulations were produced, the first with only Crioula sheep milk and the other with mixed milk (50\% sheep milk: $50 \%$ bovine milk). Both cheeses were submitted to physical-chemical and texture characterization. The cheese produced from Crioula sheep milk had a higher protein and lower fat content in relation to cheese produced from mixed milk. Greater values of hardness, chewiness and cohesiveness were found in the texture of cheeses made from Crioula sheep milk.
\end{abstract}

Keywords: Crioula sheep, Milk, Cheese, Texture.

\footnotetext{
1 Discente de Curso de Tecnologia em Agroindústria, Instituto Federal Farroupilha - Campus Alegrete, sharavargasroque@gmail.com

2 Professor Doutor em Tecnologia de Alimentos, Instituto Federal Farroupilha - Campus Alegrete, diogo.maus@gmail.com
} 


\section{Introdução}

A Ovelha Crioula é considerada uma raça local com origem nos rebanhos introduzidos pelos jesuítas no Rio Grande do Sul durante o século XVII e do cruzamento com outras raças importadas a partir da colonização portuguesa. A raça Crioula está classificada como rara e conserva traços dos ovinos primitivos e em 1982 começou a ser preservada pela Embrapa Pecuária Sul, em Bagé-RS, sendo identificadas quatro variedades dessa raça: a Fronteira (localizada ao sul do estado do Rio Grande do Sul), a Serrana ou Crioula Preta (localizada no nordeste gaúcho e planalto catarinense), a Crioula Zebura ou Ovelha de Presépio (localizada no sul do Paraná) e a Crioula Comum ou Ovelha Ordinária (localizada acima do Paraná) (ARCOR, 2019).

A raça de ovinos Crioulos é rústica, adapta-se a diferentes condições de climática, de solo e vegetação, possuindo resistência a endoparasitas e problemas podais. A ovelha Crioula representa uma enorme importância social para os pequenos produtores rurais contribuindo para a manutenção do homem no campo (ARCOR, 2019).

A produção de leite ovino vem crescendo no Brasil, tendo sido incluída no censo agropecuário de 2017. Nesse ano foi registrado a produção de $1.652 .000 \mathrm{~L}$, sendo a região sul responsável por 20.3\% do total produzido de leite de ovelha (MAGALHÃES; LUCENA, 2019). No Rio Grande do Sul, a fronteira oeste tem destaque na criação de ovelhas Crioulas, que associada a produção de leite, se apresenta como uma alternativa sustentável de baixo investimento e de fácil implementação pela agricultura familiar, trazendo alternativas de renda para as pequenas e médias propriedades rurais.

O leite ovino apresenta maiores teores de gordura, proteínas e minerais, principalmente o cálcio, em relação aos leites de vaca ou cabra (PELLEGRINI, 2012), especialmente esse leite apresenta alto teor de proteína (5,2\%) e gordura (7,9\%) (WLASTRA, 2006), o que resulta em um alto rendimento na fabricação de queijos (aproximadamente 25\%). Praticamente toda a produção de leite de ovelha está direcionada a produção de derivados lácteos. A coloração do leite de ovelha é intensamente branca e homogênea, o que o difere do leite de vaca, pois essa característica está associada à ausência de $\beta$-caroteno, pigmento precursor do retinol (vitamina A) (PENNA, 2011).

O queijo maturado de leite de ovelha é considerado de sabor forte e marcante, principalmente devido a presença de ácidos graxos de cadeia curta e média (WLASTRA, 2006), que podem ser liberados durante a lipólise. Uma alternativa para suavizar o sabor e o aroma marcantes desse tipo de queijo é a mistura do leite de ovelha com leite de vaca. Essa mistura permite maior dispersão dos ácidos graxos de cadeia curta, equilibrando o sabor e a textura do 
queijo durante o processo de maturação. Além disso, a mistura do leite ovino e bovino é uma alternativa para as propriedades rurais em períodos sazonais, com baixa produção de leite de ovino, permitindo a padronização da produção de queijos durante todo o ano.

$\mathrm{Na}$ maturação de queijos ocorrem uma série de processos bioquímicos (glicólise, proteólise e lipólise) e microbiológicos que caracterizarão o flavor e a textura característicos de cada variedade de queijo (McSWEENEY, 2004; PERRY, 2004). A textura é um parâmetro fundamental para a avaliação dos queijos, sendo citado por Childs e Drake (2009) como o segundo fator mais importante na aceitabilidade de queijos com reduzido teor de gordura.

A textura foi definida por Bourne (1978) como o conjunto de características físicas que surgem a partir dos elementos estruturais dos alimentos, são detectados pela sensação do toque e está relacionado com a deformação, desintegração e com o fluxo dos alimentos submetidos a uma força e são medidos objetivamente por funções de massa, tempo e distâncias. A textura dos alimentos pode ser avaliada, além da avaliação sensorial, por métodos instrumentais.

O principal teste instrumental utilizado para a determinação da textura é a Análise Instrumental do Perfil de Textura (TPA). O teste simula a ação de compressão e corte dos dentes durante a mastigação, consistindo em aplicações sucessivas de forças (deformantes) ao corpo de prova, e a partir disso é possível gerar uma curva força x tempo, do qual podem ser extraídos os parâmetros de textura como a dureza, mastigabilidade, elasticidade e coesividade (BOURNE, 2002).

A mudança da textura dos queijos é devido, principalmente, à hidrólise da micela de caseína durante proteólise, pela mudança do pH (migração e a solubilização de fosfato de cálcio coloidal), mudanças na mobilidade da água associada as caseínas, à perda de umidade e a difusão do sal (McSWEENEY, 2004).

A atividade proteolítica em queijos é principalmente determinada pelo tipo e níveispresentes de coalho residual na massa do queijo, enzimas nativas do leite (como a plasmina), proteinases e peptidases do fermento lático e, ou microbiota natural do leite, proteinases exógenas ou peptidases adicionadas ao leite para acelerar a maturação, pela relação sal na umidade, pela temperatura de maturação e mudanças no pH durante a maturação (FOX, 1993; McSWEENEY, 2004). Os peptídeos, produtos da ação do coagulante, são sem gosto ou amargos e não contribuem diretamente ao sabor e aroma típicos dos queijos, entretanto sua produção, principalmente nas primeiras semanas de maturação, é essencial para suavizar a textura borrachenta e elástica do queijo. 
Não existem trabalhos sobre a produção de queijo a partir do leite de ovelha Crioula, dessa forma o objetivo do trabalho foi a elaboração, caracterização e determinação da textura de queijos maturados produzidos a partir do leite de ovelha Crioula e leite misto (50\% leite de ovelha Crioula:50\% leite bovino).

\section{Material e Métodos}

O leite de ovelhas Crioulas foi obtido no setor de ovinocultura do Instituto Federal Farroupilha-campus Alegrete. As ovelhas foram alimentadas com a pastagem típica do bioma pampa. O leite integral bovino da raça Jersey foi obtido no setor de bovinocultura de leite do campus. Foram realizados 2 tratamentos para a produção dos queijos, sendo o primeiro somente com leite de ovelha Crioula e o segundo uma mistura (1:1) de leite de ovelha Crioula e leite bovino.

O processamento e maturação do queijo ocorreu no setor de Agroindústria do campus. Para o processamento, o leite foi aquecido a $35^{\circ} \mathrm{C}$ e adicionado de cultura láctica composta por Lactococcus lactis ssp. lactis, Lactococcus lactis ssp. cremoris, Lactococcus lactis ssp. lactis biovar. diacetylactis, e Leuconostoc (Sacco Brasil ${ }^{\circledR}$, Campinas, SP, Brasil), cloreto de cálcio (200 mg/Kg) e coagulante Ha La 1175 (Chr. Hansen ${ }^{\circledR}$, Valinhos, SP, Brasil) em quantidade suficiente para coagulação do leite em 35 minutos. O coágulo foi cortado em cubos de 1,0 cm de aresta seguido de agitação lenta e progressiva por 15 minutos. O cozimento da massa foi realizado de forma indireta com aquecimento da massa gradativamente até atingir a temperatura final de $42{ }^{\circ} \mathrm{C}$. Após o cozimento, foi realizada a dessoragem, enformagem da massa e prensagem (15 psi/15 min, 20 psi/15 min, 35 psi/30 min e 45 psi/80 min). Ao saírem da prensa, os queijos foram mantidos em salmoura $(20 \%)$ a $5{ }^{\circ} \mathrm{C}$ por 12 horas. Ao final, os queijos foram mantidos a $12{ }^{\circ} \mathrm{C}$ por 48 horas, embalados à vácuo em sacos termoencolhíveis e armazenados a $12{ }^{\circ} \mathrm{C}$ em incubadora BOD (MA 415; Marconi Equipamentos para Laboratórios Ltda, Piracicaba, SP, Brasil.) durante 90 dias.

Para as análises, os queijos foram escolhidos aleatoriamente, e em seguida, foram retiradas e desprezadas fatias de aproximadamente $0,5 \mathrm{~cm}$ das laterais e das partes superior e inferior. Para as análises de composição, a parte central da peça foi cortada em cubos e triturada em multiprocessador até obtenção de partículas de 2 a $3 \mathrm{~mm}$ que foram homogeneizadas manualmente. Este material obtido foi acondicionado em frascos de vidro e mantido sob refrigeração a $12{ }^{\circ} \mathrm{C}$, durante um período de 1 a 2 horas até o momento das análises. A composição e textura dos queijos foram avaliadas após os 90 dias de maturação.

Todas as análises de composição foram realizadas em triplicata. $\mathrm{O}$ pH foi determinado 
por método potenciométrico, em potenciômetro DM22 (Digimed, São Paulo, SP - Brasil), com introdução direta do eletrodo nas amostras (AOAC, 2006). O teor de extrato seco total e o teor de cinzas foi determinado gravimetricamente (AOAC, 2006). O teor de gordura, pelo método de Gerber (AOAC, 2006). O nitrogênio total (NT) foi determinado pelo método de Kjeldahl (AOAC, 2006). Para a obtenção da porcentagem de proteína total, multiplicou-se a porcentagem obtida de nitrogênio total pelo fator de conversão 6,38.

Para a análise de textura, os queijos foram amostrados com auxílio de uma sonda em formas cilíndricas de 2,0 cm de diâmetro por 3,0 cm de altura. A textura foi avaliada pela análise do perfil de textura (TPA), utilizando em texturômetro TA-XT2 Texture Analyzer (Stable Micro Systems Ltd., Godalming, Surrey, UK) operado pelo software Texture Expert. O experimento foi realizado em sala com temperatura ambiente $\left(25^{\circ} \mathrm{C}\right)$. O teste utilizado foi o de dupla compressão, com cilindro acrílico de $2,5 \mathrm{~cm}$ de diâmetro e uma deformação atribuída à amostra de 20\%. A distância percorrida pelo cilindro até a amostra foi de $10 \mathrm{~mm}$ com uma velocidade de 2 mm.s-1. Submeteu-se a amostra a duas compressões simulando a ação da $1^{\mathrm{a}} \mathrm{e}$ $2^{a}$ mordidas. Com a deformação da amostra, pelo software do equipamento, uma curva de força - compressão foi traçada. A partir dessa curva obtiveram-se os parâmetros primários: dureza, elasticidade e coesividade; e secundário: mastigabilidade, que compõem características mecânicas dos queijos (FOX et al., 2000). A análise de textura foi realizada em quintuplicata.

Os dois tratamentos do queijo foram produzidos no mesmo dia a partir da mesma batelada de leite bovino e de leite de ovelha Crioula. Os dados da composição e textura dos queijos foram avaliados por Análise de Variância (ANOVA) e teste de Tukey para comparação das médias em nível de significância de 5\%, em software Statistica (StatSoft Inc., Tulsa, OK).

\section{Resultados e Discussão}

A Tabela 1 apresenta os valores para a composição físico-química do leite de ovelha Crioula e do leite misto (ovelha e bovino) utilizados para a produção dos queijos maturados.

Os leites apresentaram variação significativa $(p \leq 0,05)$ de composição em relação ao teor de gordura, proteína e extrato seco total. O leite de ovelha Crioula apresentou baixo teor de gordura $(1,8 \%)$ e alto teor proteico $(7,15 \%)$. O leite misto, no qual foram misturadas proporções iguais de leite de ovelha crioula e leite bovino, apresentou maior teor de gordura $(2,5 \%)$ e menor teor proteico $(4,92)$. Os valores de $\mathrm{pH}$ e cinzas não diferiram significativamente entre as amostras de leite.

O leite de ovelha crioula apresentou valores de gordura menores que os esperados para esse tipo de leite, que é em média 7,8\%, enquanto que o teor proteico está acima da média para 
leites de ovelhas $(5,2 \%)$ (WALSTRA, 2006). A literatura apresenta os teores médios da composição do leite de ovelha, porém não foram encontrados estudos com a composição específica para a raça Crioula.

Tabela 1. Composição físico-química do leite de ovelha Crioula e do leite misto (ovelha e vaca).

\begin{tabular}{ccc}
\hline Análises & $\begin{array}{c}\text { Leite Ovelha } \\
\text { Crioula* }\end{array}$ & $\begin{array}{c}\text { Leite Misto (Ovelha e } \\
\text { Vaca) } *\end{array}$ \\
\hline Extrato Seco Total (\%) & $11,84^{\mathrm{b}}$ & $12,54^{\mathrm{a}}$ \\
Gordura (\%) & $1,8^{\mathrm{b}}$ & $2,5^{\mathrm{a}}$ \\
Proteína (\%) & $7,15^{\mathrm{a}}$ & $4,92^{\mathrm{b}}$ \\
Cinzas (\%) & $0,85^{\mathrm{a}}$ & $0,86^{\mathrm{a}}$ \\
pH & $6,80^{\mathrm{a}}$ & $6,80^{\mathrm{a}}$ \\
\hline
\end{tabular}

Médias com letras iguais, na mesma linha, não diferem significativamente entre si $(\mathrm{p}>0,05)$. Fonte: Própria (2020)

Os valores encontrados para a composição físico-química dos queijos maturados produzidos a partir de leite de ovelha Crioula e leite misto são apresentados na Tabela 2.

Tabela 2. Composição físico-química dos queijos maturados de leite de ovelha Crioula e do leite misto.

\begin{tabular}{ccc}
\hline Análises & $\begin{array}{c}\text { Queijo Leite Ovelha } \\
\text { Crioula }\end{array}$ & Queijo Leite Misto \\
\hline Extrato Seco Total (\%) & $53,11^{\mathrm{b}}$ & $58,54^{\mathrm{a}}$ \\
Umidade (\%) & $45.89^{\mathrm{a}}$ & $41.46^{\mathrm{b}}$ \\
Gordura (\%) & $12,0^{\mathrm{b}}$ & $18,0^{\mathrm{a}}$ \\
Extrato Seco Desengordurado (\%) & $41,11^{\mathrm{a}}$ & $40,54^{\mathrm{a}}$ \\
Gordura no Extrato Seco (\%) & $22,60^{\mathrm{b}}$ & $30.75^{\mathrm{a}}$ \\
Proteína (\%) & $30,71^{\mathrm{a}}$ & $28,96^{\mathrm{b}}$ \\
Cinzas (\%) & $5,78^{\mathrm{b}}$ & $6,68^{\mathrm{a}}$ \\
$\mathrm{pH}$ & $5,80^{\mathrm{a}}$ & $5,70^{\mathrm{a}}$ \\
\hline Médias com letras iguais, na mesma linha, não diferem significativamente entre si $(\mathrm{p}>0,05)$.
\end{tabular}
Fonte: Própria (2020)

Seguindo a tendência da composição do leite, os queijos produzidos somente com leite de ovelha crioula apresentaram alto valor proteico e baixo teor de gordura. O extrato seco total do queijo produzido com leite de ovelha Crioula foi menor em relação ao queijo produzido com leite misto, esse fato pode ser atribuído ao baixo teor de gordura encontrado do leite de ovelha crioula.

Em relação a umidade e gordura no extrato seco, os queijos produzidos com leite de ovelha Crioula e leite misto podem ser classificados como queijos de média umidade e semigordos, de acordo com o Regulamento Técnico de Identidade e Qualidade de Queijos (BRASIL, 1996).

Estudos que determinaram a composição de queijos produzidos a partir de leite de ovelha com o mesmo tempo de maturação, encontraram valores maiores para o teor de gordura 
(CODA, et al., 2006; FALLICO, et al., 2006; FREITAS; MALCATA, 2000). Não foram encontrados, para fins de comparação, estudos sobre queijo produzidos a partir de leite de ovelha Crioula. Queijos de ovelha normalmente apresentam valores superiores a $40 \%$ de gordura no extrato seco. No caso do queijo de leite de ovelha Crioula esse teor não ultrapassou $30 \%$, o que pode ser atribuído ao baixo teor de gordura inicial do leite.

O queijo de leite de ovelha Crioula apresentou $\mathrm{pH}$ final de 5,8 e o queijos produzido a partir de leite misto apresentou pH final de 5,7. Não houve diferença significativa de pH entre os tratamentos, estando os valores dentro da faixa esperada para queijos com 90 dias de maturação. O desenvolvimento do $\mathrm{pH}$ é dependente da cultura láctea, que produz ácido láctico e enzimas, preservando e propiciando o processo de maturação dos queijos (WALSTRA, 2006).

O perfil de maturação dos queijos é dependente do coalho residual e das enzimas da cultura láctea utilizada durante o processamento dos queijos. Para a produção dos queijos maturados foi utilizada uma cultura aromatizante, que além da produção de ácido láctico, promove o desenvolvimento do sabor, aroma e textura do queijo.

Para avaliar a textura dos queijos maturados de leite de ovelha Crioula e leite misto foi utilizada a análise de perfil de textura (Tabela 3).

$\underline{\text { Tabela 3. Perfil de textura (TPA) dos queijos de leite de ovelha Crioula e leite misto. }}$

\begin{tabular}{ccc}
\hline Parâmetros & $\begin{array}{c}\text { Queijo Leite } \\
\text { Ovelha Crioula }\end{array}$ & $\begin{array}{c}\text { Queijo Leite } \\
\text { Misto }\end{array}$ \\
\hline Dureza (N) & $436,61^{\mathrm{a}}$ & $373,37^{\mathrm{b}}$ \\
Mastigabilidade (N) & $142,64^{\mathrm{a}}$ & $51,75^{\mathrm{b}}$ \\
Coesividade * & $0,33^{\mathrm{a}}$ & $0,14^{\mathrm{b}}$ \\
Elasticidade $^{*}$ & $0,99^{\mathrm{a}}$ & $0,99^{\mathrm{a}}$ \\
\hline
\end{tabular}

N-Newton *adimensional.

Fonte: Própria (2020)

Os queijos apresentaram diferenças significativas $(p \leq 0,05)$ para os parâmetros de dureza, mastigabilidade e coesividade. A elasticidade não apresentou diferença significativa $(p \geq 0,05)$ entre os tratamentos.

O queijo produzido com leite de ovelha Crioula apesentou maior dureza, mastigabilidade e coesividade que o queijo produzido com leite misto. Esses valores podem ser explicados pelo maior teor proteico e menor teor de gordura do queijo produzido com leite de ovelha quando comparado ao queijo produzido a partir do leite misto. Durante o processamento de queijos, a gordura fica retida fisicamente na rede proteica formada durante a coagulação do leite. Essa retenção da gordura favorece a maciez, sendo que quanto maior o teor de gordura menores serão os valores de dureza, mastigabilidade e coesividade do queijo (FOX, 2000). 
A dureza é definida como a força requerida para comprimir um alimento entre os molares, para se obter uma deformação. Mastigabilidade é a energia necessária para mastigar um alimento sólido até o ponto de ser engolido (SZCZESNIAK, 1963; FOX et al., 2000). Dessa forma, os resultados de dureza e mastigabilidade demonstram que o queijo produzido a partir do leite misto exige uma força menor para atingir a deformação (menos firme) e menos energia é necessária para mastigá-los até estarem prontos para serem deglutidos, corroborando com os resultados obtidos de teor de gordura nos queijos (Tabela 2).

A coesividade é definida como a extensão que o queijo pode ser deformado até que haja ruptura. O menor teor de gordura no queijo produzido com leite de ovelha Crioula em relação ao queijo produzido com leite misto, permitiu a formação de uma rede proteica mais coesa, resultando em uma estrutura mais compacta, com maior quantidade de água imobilizada e consequentemente mais resistente a mordida.

Por sua vez, a elasticidade é a taxa pela qual um material deformado volta à sua condição original, após ser removida a força deformante. Portanto, a elasticidade está diretamente relacionada a rede proteica formada durante o processo de coagulação, e que sofre modificações durante a proteólise. Apesar dos queijos diferirem significativamente em relação ao teor de proteína (Tabela 2$)$, essa diferença não afetou significativamente $(p \geq 0,05)$ a elasticidade dos queijos.

Portanto, nesse estudo, podemos afirmar que os queijos produzidos com leite misto, ovino e bovino, apresentaram maior maciez e relação aos queijos de leite de ovelha Crioula. Esse resultado deve ser complementado com a análise sensorial, objetivando a confirmação dos resultados instrumentais pelos consumidores.

\section{Conclusões}

Os queijos produzidos a partir de leite de ovelhas Crioulas e leite misto, ovino e bovino, foram classificados como queijos de baixa umidade e semigordos, sendo que o queijo de leite misto apresentou maior maciez em relação ao queijo produzido somente com leite de ovelha Crioula. A produção de ambos os queijos são alternativas viáveis para agregar renda às propriedades criadoras de ovelhas Crioulas.

\section{Referências}

AOAC - Association of Official Analytical Chemists. Official methods of analysis of AOAC International. Washington, 2006. 
ARCO. Padrões raciais. Disponível em:

<http://www.arcoovinos.com.br/index.asp?pag=padroes.asp\#>. Acesso em: 23 dez. 2019.

BOURNE, M. C. Texture profile analysis. Food Technol., v. 32, n. 7, p. 62-66, 72, 1978.

BOURNE, M. Food Texture and Viscosity: Concept and Measurement. 2nd ed. San Diego: Academic Press, 2002.415p.

BRASIL. Ministério da Agricultura, Pecuária e Abastecimento. Regulamento Técnico de Identidade e Qualidade de Queijos. Brasília, 2006

CHILDS, J. L., DRAKE, M. Consumer perception of fat reduction in cheese. J. Sens. Stud. 24, 902-921. 2009.

CODA R., BRECHANY E., DE ANGELIS M., DE CANDIA S., DI CAGNO R. \& GOBBETTI M. Comparison of the Compositional, Microbiological, Biochemical, and Volatile Profile Characteristics of Nine Italian Ewes' Milk Cheeses. Journal of Dairy Science. 89: 4126-4143, 2006.

FALLICO V., TUMINELLO L., PEDILIGGIERI C., HORNE J., CARPINO S., LICITRA G. Proteolysis and Microstructure of Piacentinu Ennese Cheese Made Using Different Farm Technologies. Journal of Dairy Science. 89: 37-48, 2006.

FOX P.F. Cheese: An Overview. In: Fox P.F. (eds) Cheese: Chemistry, Physics and Microbiology. Springer, Boston, MA, 1993.

FOX; McSWEENEY, P. L. H. Dairy chemistry and biochemistry. London: Blackie Academic \& Professional, 1998. 478 p.

FOX, P. F.; GUINEE, T. P.; COGAN, T. M. et al. Fundamentals of Cheese Science. Gaithersburg, Maryland: Aspen Publishers. 2000. 587p.

FREITAS C. \& MALCATA F.X. Microbiology and Biochemistry of Cheeses with Appélation d'Origine Protegeé and Manufactured in the Iberian Peninsula from Ovine and Caprine Milks. Journal of Dairy Science. 83: 584-602, 2000.

KRAMER \& SZCZENIAK, A. S. Texture measurements of foods. Boston: D. Reidel. Publishing Company, 1973. 175 p.

MAGALHAES, K. A.; LUCENA, C. C. de. Características e evolução da ovinocultura a partir dos dados defi nitivos do Censo Agropecuário de 2017. Sobral: Embrapa Caprinos e Ovinos, 2019.

MCSWEENEY, P.L.H.; FOX P.F.; LUCEY J.A.; JORDAN K.N.; COGAN T.M. Contribution of the indigenous microflora to the maturation of Cheddar cheese. Int. Dairy J. 1993; 3: 613634 
PELLEGRINI L., G.; CASSANEGO, D. B; GUSSO, A. P.; MATTANNA, P.; SILVA, S. V. Características físico-químicas de leite bovino, caprino e ovino. Synergismus scyentifica UTFPR, Pato Branco, 07, 2012.

PENNA, C. F. A. M. Produção e parâmetros de qualidade de leite e queijos de ovelhas Lacaune, Santa Inês e mestiças submetidas a dietas elaboradas com soja ou linhaça. Universidade Federal de Minas Gerais. 2011, 154 p.

PERRY, Katia S. P.. Queijos: aspectos químicos, bioquímicos e microbiológicos. Química. Nova, São Paulo, v. 27, n. 2, p. 293-300, 2004.

SZCZESNIAK, A. S. Classification of textural characteristics. J. Food Sci. V. 28, n. 4, p. 385389, 1963.

WALSTRA, P.; JENNESS, R. Dairy chemistry and physics. Nova York: John Wiley e Sons, 2006 . 